\title{
Evaluation of Treatment Outcomes in Oromandibular Dystonia Using Surface Electromyography: A Case Series
}

\author{
Yeong-Gwan Im, Jae-Hyung Kim, Byung-Gook Kim \\ Department of Oral Medicine, Dental Science Research Institute, School of Dentistry, \\ Chonnam National University, Gwangju, Korea
}

Received December 11, 2021

Revised December 18, 2021

Accepted December 18, 2021
Correspondence to:

Byung-Gook Kim

Department of Oral Medicine, Dental Science

Research Institute, School of Dentistry,

Chonnam National University, 33 Yongbong-

ro, Buk-gu, Gwangju 61186, Korea

Tel: +82-62-530-5574

Fax: +82-62-530-5679

E-mail: bkkim@jnu.ac.kr

https://orcid.org/0000-0002-3602-4720
Purpose: Oromandibular dystonia is a neurological disorder that affects the jaw and lower face muscles, often resulting in abnormal repetitive movement of the jaw and perioral structures. The purpose of this study was to assess the effectiveness of surface electromyography (EMG) in evaluating the treatment outcome of oromandibular dystonia.

Methods: Based on a retrospective review of medical records, we analyzed the data of four patients who received medication or botulinum toxin injection, as well as surface EMG of the jaw muscles before and after treatment. We assessed the patients' clinical characteristics and the results of surface EMG before and after treatment.

Results: The case series included one female and three males, and the age range was 6578 years. Based on the clinical features, two subjects were classified as jaw deviation and the remaining two were as jaw closing. Dystonic patterns revealed by surface EMG varied, including phasic, tonic, and mixed contraction patterns. EMG amplitude after treatment was lower than pre-treatment value in all four subjects, suggesting improved clinical signs and symptoms. One subject who received clonazepam and another who received botulinum toxin injection showed a remarkable reduction in EMG amplitude within a normal range.

Conclusions: Surface EMG can be used to effective evaluate treatment outcomes in patients with oromandibular dystonia. It could be considered as an adjunctive diagnostic tool in managing patients with dystonia.

Key Words: Dystonia; Electromyography; Oromandibular dystonia; Surface electromyography; Treatment outcome

\section{INTRODUCTION}

Oromandibular dystonia (OMD) is a neurological disorder involving the jaw and lower facial muscles. Patients often show abnormal repetitive movements or stereotypic posture of the jaw, tongue, and perioral structures [1]. Involuntary movements commonly seen in patients with OMD include jaw closing, jaw opening, lateral grinding or clenching teeth, tongue thrusting, lip-smacking, or a combination thereof [2-4]. The clinical diagnosis of OMD is confusing or difficult in the absence of established diagnostic criteria; however, various diagnostic guidelines have been proposed [5-7]. The American Academy of Oral Medicine suggests physical and speech therapy, massage, biofeedback, acupuncture, occlusal appliance therapy, pharmacologic therapy, botulinum toxin injection, and surgery for the management of OMD [7]. Effective pharmacologic agents include anticholinergics, baclofen, carbamazepine, and benzodiazepines [8]. Currently, botulinum toxin injection is the first line of treatment for OMD. The jaw-closing OMD responds most effectively, while the lingual type is the most difficult to treat [9]. 
Surface electromyography (EMG) is an objective method to obtain and analyze myoelectric signals related to muscle activity using a skin sensor. Surface EMG has been used to diagnose temporomandibular disorders [10-13], assess muscle function in a patient with malocclusion [14-16], and evaluate neurological diseases such as OMD $[17,18]$.

Surface EMG has several advantages for use in dental clinics. The equipment of surface EMG is inexpensive and easier to use than needle EMG. Since the sensor utilizes surface electrodes, the measurement procedure is non-invasive. Thus, it is advantageous in obtaining patient's consent for examination.

However, few reports are available on the application of surface EMG in evaluating treatment results of patients with OMD. Therefore, in this study, we evaluated the effectiveness of surface EMG in assessing treatment outcomes in OMD.

\section{MATERIALS AND METHODS}

The study was exempted from ethics approval of the Chonnam National University Dental Hospital Institutional Review Board. We reviewed the medical records of patients who were diagnosed with OMD and treated with systemic medications or botulinum toxin injection into the jaw muscles involved. Patients who had complete medical records and underwent surface EMG before treatment and during or after treatment were selected for further investigation. We assessed the clinical features of the patients during the initial diagnostic phase and evaluated the results of surface EMG examination.

Subjects were diagnosed with OMD based on history and clinical findings. The clinical examination included resting jaw movement or jaw muscle activities, muscle tenderness with manual palpation, and the presence of muscle hypertrophy. According to the symptoms and clinical findings, subjects were assigned to one of the three OMD subtypes (jaw deviation, jaw closing, or mixed).

The EMG examination and recording procedure were performed in an isolated, quiet room containing a dental chair with controlled illumination and temperature. The subject was seated upright in the dental chair with the head erect. The subject's eyes were open, and physiological blinking was not restricted. Myoelectric signals were recorded under resting jaw condition.

Myoelectric signals were detected with a bipolar surface electrode configuration and a single differential EMG system. Disposable, monopolar, disc-type, $\mathrm{Ag} / \mathrm{AgCl}$ surface electrodes $10 \mathrm{~mm}$ in diameter with sticky gel (T246H; Bio Protech, Wonju, Korea) were attached to the skin after vigorous rubbing with alcohol cotton pads. A single monopolar reference electrode was placed over the skin of the spinous process of the seventh cervical vertebra. Pairs of surface electrodes were located on the skin of the anterior portion of the temporalis muscle (TA), superficial masseter muscle (MM), and anterior belly of the digastric muscle (DA) on both sides. The center-to-center distance between electrode pairs was fixed at $20 \mathrm{~mm}$, and the electrodes were secured with adhesive tape. The positioning of the surface electrode pairs on TA and MM was described in a previous study [19]. A pair of electrodes was placed over the skin of DA, about halfway between the 'Menton' anatomical landmark and the hyoid attachments.

EMG signals from each electrode arrangement were amplified using an eight-channel single differential amplifier (K7 EMG PRE-AMP; Myotronics, Inc., Kent, WA, USA). Input impedance was $>20 \mathrm{M} \Omega$, the common mode rejection ratio was $>110 \mathrm{~dB}$, the instrument noise voltage was $<0.2$ $\mu \mathrm{V}$, and the maximum output voltage was $2.048 \mathrm{mV}$. The signals were band-passed at 15 to $400 \mathrm{~Hz}$ and band-stop filtered at $60 \mathrm{~Hz}$. The raw signals were digitized by a 12-bit analog-to-digital converter at a sampling rate of $690 \mathrm{~Hz}$, amplified, and stored in a personal computer. The EMG signals were analyzed using K7 software (Myotronics-Noromed Inc.). The average rectified value (in microvolts) served as the amplitude variable for the EMG signal.

\section{RESULTS}

\section{Subject 1}

A 72.4-year-old female complained of involuntary tooth grinding and showed repetitive lateral jaw movements involving the left and right sides during clinical examination (Table 1). Surface EMG revealed phasic contraction of the TA and MM and mild tonic activities of the DA in the resting condition. Pharmacologic therapy was administered, 
Table 1. History and clinical findings of the subjects

\begin{tabular}{|c|c|c|c|c|}
\hline Variable & $\begin{array}{l}\text { Subject } 1 \\
(F, 72.4 y)\end{array}$ & $\begin{array}{l}\text { Subject } 2 \\
(\mathrm{M}, 78.3 \mathrm{y})\end{array}$ & $\begin{array}{l}\text { Subject } 3 \\
(\mathrm{M}, 65.4 \mathrm{y})\end{array}$ & $\begin{array}{l}\text { Subject } 4 \\
(\mathrm{M}, 69.6 \mathrm{y})\end{array}$ \\
\hline Dystonia type (clinical) & Jaw deviation & Jaw deviation & Jaw-closing & Jaw-closing \\
\hline Dystonia pattern (EMG) & Phasic & Mixed & Phasic & Tonic, partially phasic \\
\hline Symptom & Involuntary tooth grinding & $\begin{array}{l}\text { Involuntary tooth } \\
\text { grinding }\end{array}$ & $\begin{array}{l}\text { Involuntary teeth } \\
\text { clenching, toothache }\end{array}$ & $\begin{array}{l}\text { Involuntary teeth biting, } \\
\text { jaw pain, headache }\end{array}$ \\
\hline Medical condition & $\begin{array}{l}\text { Hypertension, diabetes } \\
\text { mellitus }\end{array}$ & $\begin{array}{l}\text { Diabetes mellitus, } \\
\text { gastroesophageal reflex } \\
\text { disease }\end{array}$ & $\begin{array}{l}\text { Angina, reflex } \\
\text { esophagitis, gastritis }\end{array}$ & $\begin{array}{l}\text { Diabetes mellitus, } \\
\text { cerebellar ataxia, drug- } \\
\text { induced tremor }\end{array}$ \\
\hline $\begin{array}{l}\text { Jaw movement/ } \\
\text { muscle activity }\end{array}$ & $\begin{array}{l}\text { Repetitive lateral jaw } \\
\text { movement ( } 3 \mathrm{~mm} \text { to left } \\
\text { side then } 3 \mathrm{~mm} \text { to right } \\
\text { side) }\end{array}$ & $\begin{array}{l}\text { Repetitive lateral jaw } \\
\text { movement (40/min) }\end{array}$ & $\begin{array}{l}\text { No jaw movement but } \\
\text { rhythmic contraction of } \\
\text { masseter \& temporalis }\end{array}$ & None \\
\hline Muscle tenderness & None & LTA $(+++)$, RTA (+++) & None & $\begin{array}{l}\operatorname{LTA}(++), \operatorname{RTA}(+), \operatorname{LMM}(++), \\
\operatorname{RMM}(++)\end{array}$ \\
\hline Muscle hypertrophy & None & LTA, RTA & LMM, RMM & RTA \\
\hline Additional diagnosis & Xerostomia & $\begin{array}{l}\text { Right TMJ arthralgia, } \\
\text { myalgia of temporalis }\end{array}$ & Tooth sensitivity & $\begin{array}{l}\text { Myalgia of masseter } \\
\text { \& temporalis, disc } \\
\text { displacement without } \\
\text { reduction of right TMJ }\end{array}$ \\
\hline
\end{tabular}

F, female; M, male; EMG, electromyography; TA, temporalis anterior; MM, superficial masseter; DA, digastric, anterior belly; LTA, left temporalis anterior; RTA, right temporalis anterior; LMM, left superficial masseter; RMM, right superficial masseter; TMJ, temporomandibular joint. Muscle tenderness scale: mild (+), moderate $(++)$, and severe $(+++)$.

Table 2. Surface EMG sample data before, during, or after the treatment

\begin{tabular}{|c|c|c|c|c|c|c|c|c|}
\hline Variable & \multicolumn{2}{|c|}{$\begin{array}{l}\text { Subject } 1 \\
(\mathrm{~F}, 72.4 \mathrm{y})\end{array}$} & \multicolumn{2}{|c|}{$\begin{array}{l}\text { Subject } 2 \\
(\mathrm{M}, 78.3 \mathrm{y})\end{array}$} & \multicolumn{2}{|c|}{$\begin{array}{l}\text { Subject } 3 \\
(\mathrm{M}, 65.4 \mathrm{y})\end{array}$} & \multicolumn{2}{|c|}{$\begin{array}{c}\text { Subject } 4 \\
(\mathrm{M}, 69.6 \mathrm{y})\end{array}$} \\
\hline Dystonia type (clinical) & \multicolumn{2}{|c|}{ Jaw deviation } & \multicolumn{2}{|c|}{ Jaw deviation } & \multicolumn{2}{|l|}{ Jaw closing } & \multicolumn{2}{|l|}{ Jaw closing } \\
\hline $\begin{array}{l}\text { Dystonia pattern } \\
\text { (EMG) }\end{array}$ & \multicolumn{2}{|c|}{ Phasic } & \multicolumn{2}{|l|}{ Mixed } & \multicolumn{2}{|l|}{ Phasic } & \multicolumn{2}{|c|}{ Tonic, partially phasic } \\
\hline Main treatment & \multicolumn{2}{|c|}{ Clonazepam } & \multicolumn{2}{|c|}{ Baclofen \& analgesics } & \multicolumn{2}{|c|}{ Botulinum toxin injection } & \multicolumn{2}{|c|}{$\begin{array}{l}\text { Botulinum toxin injection } \\
\text { \& clonazepam }\end{array}$} \\
\hline Surface EMG $(\mu \mathrm{V})$ & Before Tx & During Tx & Before Tx & During Tx & Before Tx & After Tx & Before Tx & After Tx \\
\hline LTA & $4.2^{\mathrm{a}}$ & 0.4 & $3.0^{\mathrm{a}}$ & 1.1 & $12.4^{\mathrm{a}}$ & $5.7^{\mathrm{a}}$ & 2.5 & 1.5 \\
\hline RTA & $7.4^{\mathrm{a}}$ & 0.7 & $3.0^{\mathrm{a}}$ & 1.8 & $19.4^{\mathrm{a}}$ & $6.7^{\mathrm{a}}$ & 2.2 & 1.1 \\
\hline LMM & $11.8^{\mathrm{a}}$ & 0.8 & 2.4 & 2.4 & $31.3^{\mathrm{a}}$ & $4.6^{\mathrm{a}}$ & 2.0 & 1.7 \\
\hline RMM & $5.1^{\mathrm{a}}$ & 0.9 & $3.8^{\mathrm{a}}$ & 1.1 & $18.6^{\mathrm{a}}$ & 2.6 & 2.7 & 1.0 \\
\hline LDA & 2.0 & 1.0 & $12.5^{\mathrm{a}}$ & 0.8 & $3.4^{\mathrm{a}}$ & 1.5 & $4.8^{\mathrm{a}}$ & 1.2 \\
\hline RDA & 2.2 & 1.6 & 2.9 & 2.4 & 2.4 & 1.2 & $8.9^{\mathrm{a}}$ & 1.7 \\
\hline Recording time (s) & 30 & 15 & 15 & 30 & 15 & 15 & 15 & 15 \\
\hline
\end{tabular}

EMG, electromyography; F, female; M, male; Tx, treatment; LTA, left temporalis anterior; RTA, right temporalis anterior; LMM, left superficial masseter; RMM, right superficial masseter; LDA, left digastric, anterior belly; RDA, right digastric, anterior belly.

${ }^{a}$ Signal amplitude greater than $3.0 \mu \mathrm{V}$ was considered significantly high in a resting condition.

and the patient's signs and symptoms were effectively controlled with $1 \mathrm{mg} /$ day clonazepam. Surface EMG revealed no phasic contraction and normal resting activity (Table 2 , Fig. 1).

\section{Subject 2}

A 78.3-year-old male complained of pain on the right temporomandibular joint (TMJ), opening limitation, and involuntary parafunctional habits, including tooth grinding and jaw thrusting. During clinical examination, repetitive lateral jaw movement (40/min) was observed, suggesting dystonia of the jaw deviation type. TA on both sides showed severe tenderness and muscle hypertrophy (Table 1). Arthrocentesis and intra-articular injection of a 


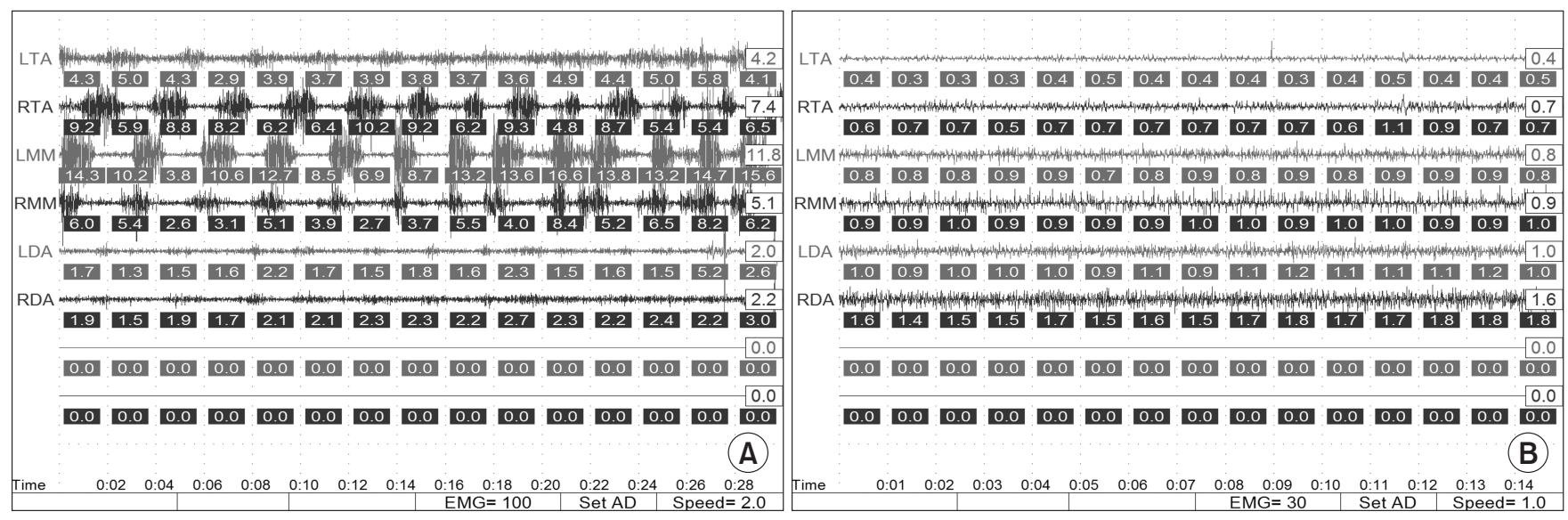

Fig. 1. Subject 1. A 72.4-year-old female with the jaw-deviation type of oromandibular dystonia and phasic contraction pattern. The surface electromyography (EMG) recording revealed a prominent phasic contraction pattern of the temporalis and masseter muscles bilaterally before treatment, which was effectively controlled with pharmacologic therapy using $1 \mathrm{mg} /$ day clonazepam. (A) Before the treatment (gain: 100 $\mu \mathrm{V} /$ division, tracing speed: $2.0 \mathrm{~s} /$ division). (B) During the pharmacologic therapy (gain: $30 \mu \mathrm{V} /$ division, tracing speed: $1.0 \mathrm{~s} /$ division). LTA, left temporalis anterior; RTA, right temporalis anterior; LMM, left superficial masseter; RMM, right superficial masseter; LDA, left digastric, anterior belly; RDA, right digastric, anterior belly. Numbers added to the tracing records denote the amplitude of the myoelectric signal (unit: $\mu \mathrm{V}$ ).

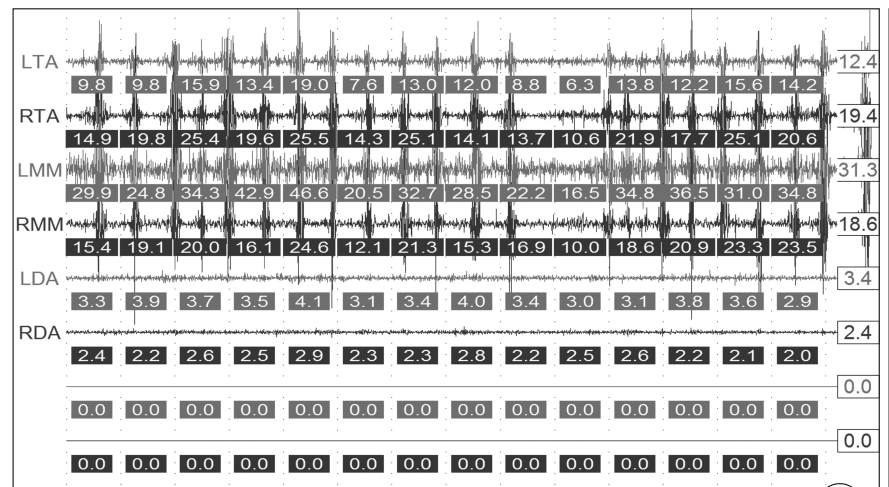

(A)

\begin{tabular}{lllllllllllllll|l} 
Time & $0: 01$ & $0: 02$ & $0: 03$ & $0: 04$ & $0: 05$ & $0: 06$ & $0: 07$ & $0: 08$ & $0: 09$ & $0: 10$ & $0: 11$ & $0: 12$ & $0: 13$ & $0: 14$ \\
\hline
\end{tabular}



Fig. 2. Subject 3. A 65.4-year-old male with the jaw-closing type and phasic contraction pattern. The surface electromyography (EMG) recording revealed regular phasic contractions of the temporalis and masseter muscles bilaterally before treatment. Botulinum toxin therapy was mainly effective in normalizing the resting activity of the masseter muscle. (A) Before the treatment (gain: $200 \mu \mathrm{V} /$ division, tracing speed: $1.0 \mathrm{~s} /$ division). (B) After the botulinum toxin injection (gain: $200 \mu \mathrm{V} /$ division, tracing speed: $1.0 \mathrm{~s} /$ division). LTA, left temporalis anterior; RTA, right temporalis anterior; LMM, left superficial masseter; RMM, right superficial masseter; LDA, left digastric, anterior belly; RDA, right digastric, anterior belly. Numbers added to the tracing records denote the amplitude of the myoelectric signal (unit: $\mu \mathrm{V}$ ).

corticosteroid relieved the joint symptoms. Therapy with clonazepam was ineffective in controlling dystonia symptoms. Surface EMG revealed a mixed pattern of various types of tonic contractions. Pharmacotherapy with baclofen reduced the dystonia symptoms significantly. However, the patient could not tolerate the adverse drug reactions, and the treatment was discontinued after three weeks. Occlusal adjustment was performed on teeth with excessive contacts. Surface EMG showed that dystonic activity was significantly reduced, and the amplitude was close to the normal range although not eliminated (Table 2).

\section{Subject 3}

A 65.4-year-old male complained of involuntary clenching and associated generalized tooth sensitivity. The patient showed rhythmic contractions of MM and TA muscles and hypertrophy of the MM muscle (Table 1). Surface EMG showed phasic contractile activities of MM and TA muscles 
(88/min). Pharmacologic agents, including clonazepam, diazepam, and baclofen, were ineffective. A botulinum toxin (Botox; Allergan, Irvine, CA, USA) was injected bilaterally into the MM and TA muscles, which almost resolved the patient's signs and symptoms. Surface EMG showed that botulinum toxin therapy was effective in normalizing the resting activity of the MM muscle (Table 2, Fig. 2).

\section{Subject 4}

A 69.6-year-old man had several complaints, such as involuntary tooth biting, jaw pain, and headache symptoms. Clinical examination showed moderate tenderness to palpation in the TA and MM bilaterally. The patient was diagnosed with disc displacement without reduction of the right TMJ as well as myalgia of the jaw muscles (Table 1). Surface EMG revealed a tonic contraction with partially phasic features, especially in the TA and DA. Analgesics and physical therapy were not effective in relieving the patient's symptoms. Botox (Allergan; 100 IU in total) was injected bilaterally into the MM and TA muscles, followed by $1 \mathrm{mg} /$ day clonazepam. Subjective pain and muscle tenderness were significantly reduced during the follow-up visits. Surface EMG recording revealed a normal amplitude range in all muscles (Table 2).

\section{DISCUSSION}

Among the four subjects diagnosed with OMD clinically in this study, two subjects showed jaw deviation and the other two manifested jaw closing. Yoshida [5] reported that 59.5\% of 385 patients manifested the jaw-closing OMD, 12.7\% jaw-opening type, 5.5\% jaw-deviation, and 25.5\% lingual dystonia. In the study of Slaim et al. [4], the jawopening type of OMD was the most common accounting for $62.1 \%$ of 240 patients, followed by jaw closing (20.0\%) and mixed type (17.9\%). In addition, lingual dystonia was identified in $26.7 \%$ of the patients.

In the present study, surface EMG was used to assess TA, $\mathrm{MM}$, and DA muscles, which are often affected by dystonia. Because they are close to the skin surface, surface EMG was easily used for assessment. Bakke et al. [17] reported that dystonic activity was frequently found in the TA, DA, and lateral pterygoid muscles, based on the EMG examination of the masticatory, lip, and tongue muscles.

The surface EMG pattern of dystonic contractions in the four subjects at rest varied, including those of phasic, tonic, and mixed contractions. Kim et al. [18] suggested several surface EMG features of patients with OMD, such as phasic and tonic contraction, synchronous contraction, and high signal amplitude under resting condition. Muscles with dystonia exhibit persistent involuntary firing of motor unit action potentials with needle EMG at rest [20].

Treatments were effective in all four subjects. In subjects 1 and 3, dystonic symptoms were almost resolved, and the surface EMG results correlated with the clinical findings. For example, the surface EMG of subject 1 treated with clonazepam showed features of normal signal amplitude without dystonic activity. The mean resting amplitude of the TA and MM muscles in the elderly is 0.5 to $1.0 \mu \mathrm{V}$ [21], and it is generally within $3.0 \mu \mathrm{V}$ [22]. These results suggest that surface EMG can be used to evaluate the effectiveness of specific treatments for OMD and monitor the course of treatment. For example, Yoshida et al. [23] demonstrated clinical improvement and reduced EMG activity following intramuscular injection of diluted lidocaine and alcohol in patients with OMD.

OMD and temporomandibular disorders often coexist [4,24-26]. Subject 2 was first diagnosed with arthralgia and disc displacement with reduction of the right TMJ, myalgia of TA, and later OMD. Subject 4 was diagnosed with myalgia of MM and TA, disc displacement without reduction of the right TMJ. Muscle hypertrophy was observed in subjects 2, 3, and 4. Subjects 2 and 4 underwent regular TMD treatment, including physical therapy, analgesic medication, arthrocentesis, intra-articular steroid injection as well as treatments for OMD.

When interpreting the surface EMG data presented in Table 2, it should be noted that they are not absolute values but closely associated with typical dystonic activity in the recorded data. In patients with OMD, monitored muscle activity continuously changes over time. Therefore, depending on the measurement time, the amplitude of EMG activity may vary significantly, or different types of muscle contraction may be observed [18].

Although surface EMG has many advantages, it also has several limitations. EMG signals cannot be obtained from 
deep jaw muscles such as lateral and medial pterygoids. It is difficult to access the inside of the oral cavity and measure signals from intraoral muscular structures, including the tongue. Further, it is not easy to obtain an isolated signal from a specific perioral or facial muscle by distinguishing other neighboring muscles. Therefore, it is not possible to evaluate all types of OMD using only surface EMG. These technical challenges can be resolved by using needle EMG.

This study has the following limitations. First, only a few subjects were included. Follow-up studies that include a large number of subjects exposed to various treatments are recommended. Second, surface EMG was measured only in the resting condition. It is desirable to obtain results using other tests under different conditions. Third, the reliability of EMG raw amplitude presented in the results is questionable because the measurements are influenced by various factors. One way to solve this problem is to perform maximal voluntary muscle contraction, followed by normalization. Fourth, objective and quantitative clinical indices were not used to evaluate the severity of dystonia before and after treatment.

In conclusion, surface EMG can be used to effectively evaluate treatment outcomes in patients with OMD. It could be considered as an adjunctive evaluation tool in managing patients with dystonia.

\section{CONFLICT OF INTEREST}

No potential conflict of interest relevant to this article was reported.

\section{ORCID}

\author{
Yeong-Gwan Im \\ https://orcid.org/0000-0003-2703-1475 \\ Jae-Hyung Kim \\ https://orcid.org/0000-0001-5646-4371 \\ Byung-Gook Kim \\ https://orcid.org/0000-0002-3602-4720
}

\section{REFERENCES}

1. Albanese A, Bhatia K, Bressman SB, et al. Phenomenology and classification of dystonia: a consensus update. Mov Disord 2013;28:863-873.

2. Balasubramaniam R, Ram S. Orofacial movement disorders. Oral Maxillofac Surg Clin North Am 2008;20:273-285, vii.

3. Esper CD, Freeman A, Factor SA. Lingual protrusion dystonia: frequency, etiology and botulinum toxin therapy. Parkinsonism Relat Disord 2010;16:438-441.

4. Slaim L, Cohen M, Klap P, et al. Oromandibular dystonia: demographics and clinical data from 240 patients. J Mov Disord 2018;11:78-81.

5. Yoshida K. Oromandibular dystonia screening questionnaire for differential diagnosis. Clin Oral Investig 2019;23:405-411.

6. Defazio G, Albanese A, Pellicciari R, et al. Expert recommendations for diagnosing cervical, oromandibular, and limb dystonia. Neurol Sci 2019;40:89-95.

7. France K, Stoopler ET. The American Academy of Oral Medicine clinical practice statement: oromandibular dystonia. Oral Surg Oral Med Oral Pathol Oral Radiol 2018;125:283-285.

8. Albanese A, Di Giovanni M, Lalli S. Dystonia: diagnosis and management. Eur J Neurol 2019;26:5-17.

9. Comella CL. Systematic review of botulinum toxin treatment for oromandibular dystonia. Toxicon 2018;147:96-99.

10. Pinho JC, Caldas FM, Mora MJ, Santana-Penín U. Electromyographic activity in patients with temporomandibular disorders. J Oral Rehabil 2000;27:985-990.

11. Santana-Mora U, Cudeiro J, Mora-Bermúdez MJ, et al. Changes in EMG activity during clenching in chronic pain patients with unilateral temporomandibular disorders. J Electromyogr Kinesiol 2009; 19:e543-e549.

12. Pitta NC, Nitsch GS, Machado MB, de Oliveira AS. Activation time analysis and electromyographic fatigue in patients with temporomandibular disorders during clenching. J Electromyogr Kinesiol 2015;25:653-657.

13. Xu L, Fan S, Cai B, Fang Z, Jiang X. Influence of sustained submaximal clenching fatigue test on electromyographic activity and maximum voluntary bite forces in healthy subjects and patients with temporomandibular disorders. J Oral Rehabil 2017;44:340346.

14. Moreno I, Sánchez T, Ardizone I, Aneiros F, Celemin A. Electromyographic comparisons between clenching, swallowing and chewing in jaw muscles with varying occlusal parameters. Med Oral Patol Oral Cir Bucal 2008;13:E207-E213.

15. Piancino MG, Farina D, Talpone F, Merlo A, Bracco P. Muscular activation during reverse and non-reverse chewing cycles in unilateral posterior crossbite. Eur J Oral Sci 2009;117:122-128.

16. Ciccone de Faria Tdos S, Hallak Regalo SC, Thomazinho A, Vitti $\mathrm{M}$, de Felício CM. Masticatory muscle activity in children with a skeletal or dentoalveolar open bite. Eur J Orthod 2010;32:453458.

17. Bakke M, Larsen BM, Dalager T, Møller E. Oromandibular dystonia--functional and clinical characteristics: a report on 21 cases. Oral Surg Oral Med Oral Pathol Oral Radiol 2013;115:e21-e26.

18. Kim JH, Kim BG, Im YG. Surface electromyography for evaluating patients with oromandibular dystonia. Cranio 2021. doi: 10.1080/08869634.2021.1971448. [Epub ahead of print] 
19. Im YG, Han SH, Park JI, Lim HS, Kim BG, Kim JH. Repeatability of measurements of surface electromyographic variables during maximum voluntary contraction of temporalis and masseter muscles in normal adults. J Oral Sci 2017;59:233-245.

20. Preston DC, Shapiro BE. Electromyography and neuromuscular disorders: clinical-electrophysiologic-ultrasound correlations. 4th ed. Philadelphia: Elsevier; 2020. pp. 259.

21. Sônego MV, Goiato MC, Dos Santos DM. Electromyography evaluation of masseter and temporalis, bite force, and quality of life in elderly patients during the adaptation of mandibular implantsupported overdentures. Clin Oral Implants Res 2017;28:e169e174.

22. Im YG, Kim JH, Kim BG. Sternocleidomastoid and posterior cervical muscle coordination in response to symmetrical and asymmetrical jaw functions in normal adults. J Oral Med Pain 2015;40:115-123.
23. Yoshida K, Kaji R, Kubori T, Kohara N, Iizuka T, Kimura J. Muscle afferent block for the treatment of oromandibular dystonia. Mov Disord 1998;13:699-705.

24. Sude A, Nixdorf DR. Prevalence and clinical characteristics of patients with oromandibular dystonia seen in the orofacial pain clinic: a retrospective study. Oral Surg Oral Med Oral Pathol Oral Radiol 2020;130:169-174.

25. Sude A, Matsumoto J, Kaimal S, Petersen A, Nixdorf DR. Temporomandibular disorder-related characteristics and treatment outcomes in oromandibular dystonia patients in two different clinical settings: a cross-sectional study. J Oral Rehabil 2021;48:542-550.

26. Handa S, Shaefer JR, Keith DA. Oromandibular dystonia and temporomandibular disorders. J Am Dent Assoc 2021. doi: 10.1016/ j.adaj.2021.07.026. [Epub ahead of print] 